\title{
Head growth in cystic fibrosis following early diagnosis by neonatal screening
}

Department of Paediatrics, University of Sheffield, Sheffield

$S$ Ghosal

C J Taylor

M Pickering

J McGaw

Correspondence to: Dr C J Taylor, Department of Paediatrics, Sheffield

Children's Hospital, Western

Bank, Sheffield S10 2TH.

Accepted 7 June 1996

\author{
S Ghosal, CJ Taylor, M Pickering, J McGaw
}

\begin{abstract}
Growth in length, weight gain, and head circumference were recorded from 3 months to 4 years of age in 25 children with cystic fibrosis diagnosed by neonatal screening. Mean standard deviation (SD) scores at 3 months for length, weight, and head circumference were $-0.78,-0.91$, and -0.52 respectively. Over the first 2 years length SD scores showed a consistent improvement and stabilised at 0.1 SD below mean from 2 to 4 years. Weight SD scores remained essentially unaltered throughout, approximately 1 SD below the mean. Head circumference, however, after an initial increase from -0.52 at 3 months to -0.25 at 18 months, slowed and fell to $1 \mathrm{SD}$ below the mean at 4 years. The data suggest that head growth continues to lag behind somatic growth in children with cystic fibrosis despite early diagnosis and good nutritional management in early infancy. These data also support functional expression of cystic fibrosis transmembrane conductance regulator in the brain.

(Arch Dis Child 1996;75:191-193)
\end{abstract}

Keywords: cystic fibrosis, auxology, neonatal screening.

Improvement in nutritional support has led to better growth and long term survival in cystic fibrosis. Improvements in height and weight gain have been achieved with high energy diets and by optimising pancreatic supplementation.

Recently we showed disproportionately slow head growth in patients with cystic fibrosis in spite of aggressive nutritional support. ${ }^{1}$ However, only $7 \%$ of the patients in that study were diagnosed by neonatal screening, the majority being diagnosed on clinical grounds, including $34 \%$ who presented with meconium ileus.

In 1989 a postnatal screening service for cystic fibrosis was established in the Trent NHS region. This is run according to guidelines for disease screening, ${ }^{23}$ using an immunoreactive trypsin (IRT) assay on heelprick blood samples which has proved an effective screening test for cystic fibrosis. ${ }^{4}$ Early diagnosis has been shown to reduce morbidity and hospital stay in the first year of life, ${ }^{56}$ but no differences in somatic growth could be demonstrated in two populations of cystic fibrosis children diagnosed on alternate weeks by screening and clinical methods. ${ }^{6}$ As data on head growth were not recorded in this study by Chatfield $e t a l,{ }^{6}$ we have examined prospectively whether improvement in head circumfer- ence, weight, and height could be achieved by early nutritional support in a cohort of children with cystic fibrosis diagnosed by screening.

\section{Methods}

Using standard anthropometric techniques, a single auxologist measured occipitofrontal circumference (OFC), linear height, and weight monthly in 25 children with cystic fibrosis attending the regional cystic fibrosis centre in Sheffield. Height was measured with a Holtain stadiometer, weight by Weighmaster Babyweigher model 520/10 and Seca alpha model 770 scales, and OFC by an anthropometric tape. All children were pancreatic insufficient and were diagnosed through a postnatal screening programme. Screening was performed as a triple phase process involving initial testing of dried blood spots from the Guthrie card for IRT, followed by genetic testing of the same sample for a variety of the common cystic fibrosis mutations with confirmation by sweat electrolyte analysis.

Genotype data were available for all children: 18 were DF508 homozygous, the remainder were compound heterozygotes for DF508 and other less common mutations. All patients showed evidence of steatorrhoea. Pancreatic insufficiency was confirmed in early infancy by the presence of excess fat globules in stool and response to pancreatin supplementation. Our nutritional policy comprised a high energy ( $>120 \%$ of dietary reference value ${ }^{7}$ ) unrestricted fat diet, supplemented with sufficient pancreatin to control steatorrhoea. $\mathrm{Pa}$ tients were reviewed by a paediatric dietician at each clinic visit and regular dietary assessments were made using a computerised nutrition program (Dietplan, Forrestfield software).

\section{STATISTics}

Standard deviation (SD) scores were calculated for height, weight, and head circumference measurements. Bone age estimations were performed annually using the Tanner and Whitehouse (ii) method. ${ }^{8}$ The Student's $t$ test was used for comparison with population means and the Wilcoxon signed rank test to assess the significance between the age groups.

\section{Results}

Height, weight, and OFC values from 3 months to 4 years are presented in table 1 and graphically in fig 1(A-C) as mean SD scores. Mean length, weight, and OFC SD scores were all significantly low at 3 months compared to the population mean $(-0.78, \mathrm{p}<0.01$; 
Table 1 Mean SD scores for height, weight, and occipitofrontal head circumference (OFC) in children with cystic fibrosis grouped according to age. Values for both sexes were pooled together. The p values for Student's test are given, based on an expected mean value of zero

\begin{tabular}{|c|c|c|c|c|c|c|c|c|c|c|c|c|}
\hline \multirow{2}{*}{$\begin{array}{l}\text { Age } \\
\text { (years) }\end{array}$} & \multicolumn{4}{|c|}{ Length/height SD score } & \multicolumn{4}{|c|}{ Weight $S D$ score } & \multicolumn{4}{|c|}{ OFC SD score } \\
\hline & No & Mean & $S E$ & $p$ & No & Mean & $S E$ & $p$ & No & Mean & $S E$ & $p$ \\
\hline 0.25 & 14 & -0.78 & 0.29 & $<0.01$ & 14 & -0.91 & 0.37 & $<0.025$ & 14 & -0.52 & 0.30 & $<0.05$ \\
\hline 0.5 & 14 & -0.53 & 0.27 & $<0.05$ & 14 & -0.92 & 0.39 & $<0.025$ & 14 & -0.29 & 0.28 & NS \\
\hline 1 & 17 & -0.27 & 0.30 & NS & 17 & -0.62 & 0.40 & NS & 17 & -0.38 & 0.29 & NS \\
\hline 1.5 & 16 & -0.41 & 0.31 & NS & 16 & -0.98 & 0.31 & $<0.005$ & 16 & -0.25 & 0.29 & NS \\
\hline 2 & 17 & -0.10 & 0.28 & NS & 17 & -0.83 & 0.24 & $<0.0025$ & 16 & -0.59 & 0.20 & $<0.005$ \\
\hline 3 & 14 & -0.19 & 0.29 & NS & 15 & -1.07 & 0.30 & $<0.0025$ & 14 & -0.74 & 0.21 & $<0.0025$ \\
\hline 4 & 11 & -0.13 & 0.34 & NS & 11 & -1.06 & 0.41 & $<0.025$ & 11 & -1.05 & 0.18 & $<0.0001$ \\
\hline
\end{tabular}

$\mathrm{NS}=\mathrm{p}>0.05$.

$-0.91, \mathrm{p}<0.025 ;$ and $-0.52, \mathrm{p}<0.05$ respectively). The mean length $\mathrm{SD}$ score showed a significant improvement from -0.78 at 3 months to -0.13 at 4 years $(p<0.05)$. The weight SD score also improved from a mean of -0.91 at 3 months to -0.62 at 1 year but fell gradually to $1 \mathrm{SD}$ below the mean from 3 years onwards. In contrast to the sustained gains in height, the OFC SD score, after initial improvement from a mean of -0.52 at 3 months to -0.25 at 18 months, fell progressively to -1.05 at 4 years (Student's $t$ test: $\mathrm{p}<0.0001$ )

\section{Discussion}

There are relatively few studies on growth patterns in children with cystic fibrosis diagnosed by screening. Chatfield and colleagues ${ }^{6}$ have
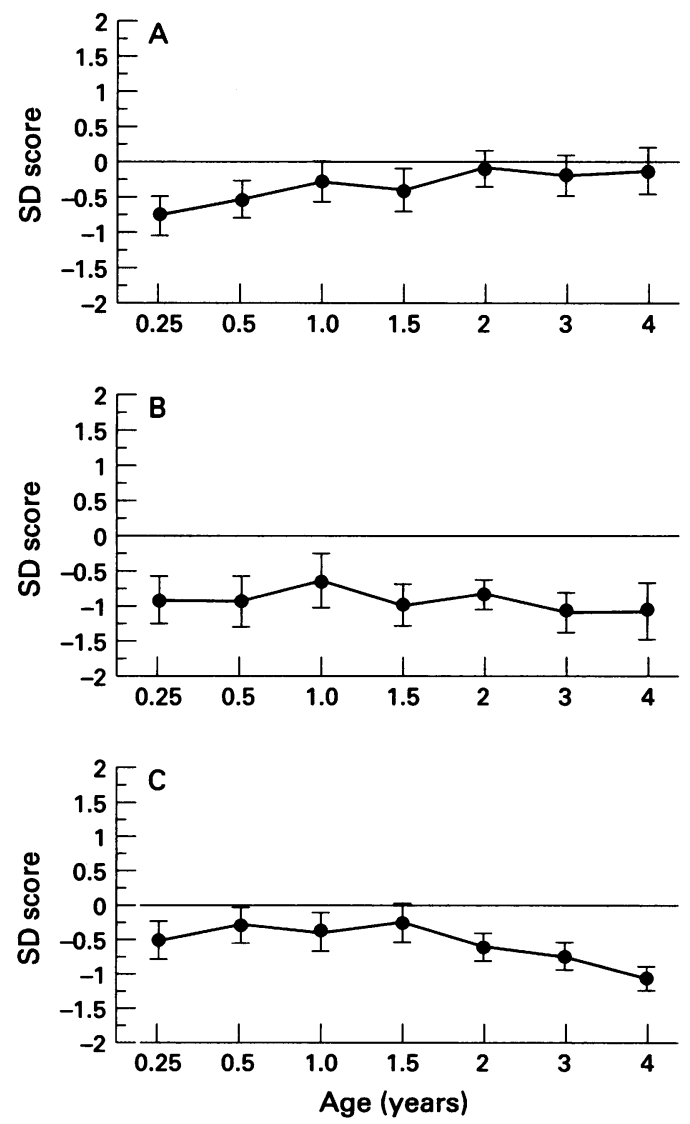

Figure 1 (A) Height SD score from 3 months to 4 years showing continuous improvement up to 4 years. (B) Weight $S D$ score from 3 months to 4 years. (C) Head circumference $S D$ score from 3 months to 4 years. Initial improvement up to 1.5 years is followed by subsequent decline to - $1 S D$ at 4 years. Error bars represent SEM. shown that somatic growth improves compared to birth data in both screened and nonscreened patients with cystic fibrosis, reaching an SD score of nearly zero at the age of 4 years. Investigators have also reported that biochemical evidence of malnutrition is present in pancreatic insufficient patients with cystic fibrosis when first diagnosed by screening. ${ }^{9}$ The progressive improvements in height and weight gain shown by the Trent children are similar to those reported in West Midlands and Welsh patients, ${ }^{6}$ although the absence of head circumference data limits direct comparison. Similar patterns for linear growth were reported in Swedish children with cystic fibrosis, ${ }^{10}$ with length SD at 3 months -1.3 below mean, improving to -0.19 at 5 years of age.

Cellular growth of the brain in the first year of postnatal life ${ }^{11}$ is reflected by an increase in head circumference. In both small for dates and proportionate infants, relatively minor undernutrition during a time of very rapid brain growth can result in a deficit in the final brain size ${ }^{12}$ and affect brain cell growth and DNA content." ${ }^{11}$ Although most of the structural alterations in the brain eventually recover to some extent, recent neuropharmacological research has revealed long lasting, and possibly permanent, changes in brain neural receptor function resulting from an early episode of malnutrition. ${ }^{13}$ The extent of malnutrition required to produce these long term alterations is unknown.

There are many factors, including hormonal imbalance and energy imbalance, which singly or in combination may contribute to growth retardation in patients with cystic fibrosis. Lee and colleagues ${ }^{14}$ proposed that growth retardation was caused by a defect in the hypothalamic-pituitary somatomedin generating system, secondary to protein malnutrition. Rosenfeld and co-workers ${ }^{15}$ also measured serum somatomedin activity by radioimmunoassay in 15 adolescents with cystic fibrosis but found concentrations within the normal range. Neither study documented hepatic function, an important omission since growth hormone regulates the elaboration by the liver of a family of insulin-like growth factors, the somatomedins. Somatomedin levels are depressed in protein malnutrition, but whether somatomedin function is always normal in cystic fibrosis or not, and under what circumstances, are questions that remain to be answered. 
In contrast to our previous report ${ }^{1}$ this study shows an initial acceleration in head growth up to the age of 18 months. However, head growth subsequently slows and the SD score at 4 years of age is similar to our earlier observations. This supports our previous conclusion that in cystic fibrosis, despite early diagnosis and careful attention to nutrition, head growth lags behind other indices of growth and development. Nutritional deficiency alone is unlikely to cause the small head size. Cystic fibrosis transmembrane conductance regulator (CFTR) expression has been reported in brain, ${ }^{16}$ although its significance is unclear. It is possible that CFTR influences CSF secretion and this may be deficient in cystic fibrosis, leading to a reduction in brain volume. Magnetic resonance imaging studies can calculate ventricular and brain volume ${ }^{17}$ and examine the maturation pattern of grey and white matter. ${ }^{18}$ This, and the availability of animal models of cystic fibrosis, ${ }^{1920}$ may provide further ways to look at critical periods of brain growth and development in this disease.

Dr Ghosal is funded by the Cystic Fibrosis trust.

1 Ghosal S, Taylor CJ, Pickering M, McGaw J, BecklesWillson N, Wales JKH. Disproportionate head growth patterns in cystic fibrosis. Arch Dis Child 1995;72:150-2.

2 Wilson JM. Principles of screening for disease. Proc $R$ Soc Med 1971;64:1255-6.

3 Holtzmann NN. Newborn screening for hereditary metabolic disorders: desirable characteristics, experience and issues. In: Kabach M, ed. Genetic issues in pediatrics, perinatology and obstetrical practice. Chicago: Yearbook Publishers, 1981:455-70.

4 Ranieri E, Ryall RG, Morris CP, et al. Neonatal screening strategy for cystic fibrosis using immunoreactive trypsinogen and direct gene analysis. $B M \mathcal{F}$ 1991;302:1237-40.
5 Wilcken B, Chalmers G. Reduced morbidity in patients with cystic fibrosis detected by neonatal screening. Lancet 1985; ii: $1319-21$.

6 Chatfield S, Owen G, Ryley HC, et al. Neonatal screening for cystic fibrosis in Wales and the West Midlands: clinical assessment after five years of screening. Arch Dis Child $1991 ; 66: 29-33$

7 Department of Health. Dietary reference values for food energy and nutrients in the United Kingdom. London: HMSO, 1991.

8 Tanner JM, Whitehouse RH, Marshall WA, Healy MJR, Goldstein H. Assessment of skeletal maturity and prediction of adult height (TW2 method). London: Academic Press, 1975 fronstein MN, Sokol RJ, Abman SH, et al. Pancreatic insufnatal screening as having cystic fibrosis. $\mathcal{F}$ Pediatr 1992;120: 533-540.

10 Karlberg J, Kjellmar I, Kristiansson B. Linear growth in children with cystic fibrosis. Acta Paediatr Scand 1991;80: 508-14.

11 Winick $M$, Rosso P. Head circumference and cellular growth of the brain in normal and marasmic children. $f$ Pediatr 1969;80:508-14.

12 Graham G. Effect of infantile malnutrition on growth. Fed Proc 1967;26:139-43.

13 Levitsky DA, Strupp BJ. Malnutrition and the brain: changing concepts, changing concerns. $\mathcal{f}$ Nutr 1995;125(suppl 8):2212-20S.

14 Lee JA, Dickinson LS, Kilgore HS, Warren RH, Elders MJ. romatomedin activity in cystic fibrosis and reserpinized rats: possible explanation
Lab Sci 1980;10:227-33.

15 Rosenfeld RG, Landon C, Lewiston N, Nagashima R, Hintz RL. Demonstration of normal plasma somatomedin concentrations in cystic fibrosis. $₹$ Pediatr 1981;99:251-4.

16 Mulberg AE, Resta LP, Wiedner EB Altschuler SM, Jefferson DM, Broussard DL. Expression and localization of the cystic fibrosis transmembrane conductance regulato mRNA and its protein in rat brain. $\mathcal{f}$ Clin Invest 1995;96:646-52.

17 Blatter DD, Bigler ED, Gale SD, et al. Quantitative volumetric analysis of brain MR: normative database spanvolumetric analysis of brain MR: normative database span-

18 Ballesteros MC, Hansen PE, Soila K. MR imaging of the developing human brain. Part 2. Postnatal development. Radiographics 1993;13:611-22.

19 Dorin JR, Dickinson P, Alton EW, et al. Cystic fibrosis in the mouse by targeted insertional mutagenesis. Nature 1992; 358:211-5.

20 Snouwaert JN, Brigman KK, Latour AM, et al. An animal model for cystic fibrosis made by gene targeting. Science 1992;257:1083-8. 